\title{
The Development of Open Source Based Citizen Collaboration Applications for Infrastructure Management: My City Report
}

\author{
Toshikazu Seto $^{\mathrm{a} *}$, Yoshihide Sekimoto ${ }^{\mathrm{b}}$, Hiroshi Omata ${ }^{\mathrm{b}}$, Hiroya Maeda ${ }^{\mathrm{b}}$, Takehiro Kashiyama ${ }^{\mathrm{b}}$, \\ Shusaku HIGASHI ${ }^{\mathrm{c}}$, Masato Fujii ${ }^{\mathrm{c}}$, and Haruyuki SEKI ${ }^{\mathrm{c}}$. \\ ${ }^{a}$ Center for Spatial Information Science, The University of Tokyo, tosseto@csis.u-tokyo.ac.jp \\ ${ }^{b}$ Institute of Industrial Science, The University of Tokyo, sekimoto@iis.u-tokyo.ac.jp,homata@iis.u-tokyo.ac.jp,maedahi@iis.u- \\ tokyo.ac.jp,ksym@iis.u-tokyo.ac.jp \\ c Georepublic Japan,higashi@georepublic.co.jp, fujii@georepublic.co.jp, hal@georepublic.co.jp \\ * Corresponding author
}

\begin{abstract}
This paper describes the development of the "My City Report" open source platform as a tool to encourage citizens to solve problems themselves as well as actively hearing and carefully considering citizens' opinions. This was accomplished by conducting demonstration experiments utilizing data from several domestic municipalities. The development was done by prototyping and its efficacy was tested in different population sizes from 15 local governments during a period of three years. These discussions showed a functional improvement based on over 300 positive feedback comments. Furthermore, the developed applications and systems were tested on a public cloud during the same period, and some municipalities received long-term submissions from citizens and road administrators. This paper details the current arrival points and issues concerning civil collaboration and management efficiency targeting roads based on data driving. We discuss the current goals and issues concerning citizens' collaboration and management efficiency for roads based on data driving.
\end{abstract}

Keywords: Open Government, Open Source, Road Management, Citizen Complaints, Citizen Collaboration

\section{Introduction}

Citizens report and provide feedback concerning areas such as infrastructure inspection by means of Information and Communication Technology using smartphones and a Web service. Since the early 2000s, a number of web submission systems such as "FixMyStreet" and "SeeClickFix" has been developed. "Open 311" guarantees interoperability regarding the structure of these contributions and standardized data processing, offering a one-stop administrative reporting service, mainly in urban areas of Europe and the United States.

As a background to this current situation, citizenoriented feedback using maps has also been seen in participatory geographic information systems (PGIS), which have been studied since the 1990s. Schuurman (2000) declared criticism of GIS to be organized in three periods; the technology adopted a subtler analysis and expressed a great commitment to geography. Haklay (2013) also argues that the process of creation and use of geographical information is fundamentally democratized in the neogeography. Pánek (2016) pointed out the progress of Internet technology, where users were able to overcome the technical gap and become "neocartographers" without requiring knowledge of GIS, considering the democratization of maps and geospatial information. By doing so, new possibilities in citizen participation have emerged.

Recently in Japanese situation, "Chiba-repo"which was developed by the Chiba City Office - and "FixMyStreet Japan" is commonly used by multiple local governments and is a representative example of web-based citizen reporting and cooperative systems. In response to diversifying and complicated infrastructure tasks, it is necessary to respond to citizen reporting efficiently within a municipality, shorten response time (Xu et al., 2017), and utilize the appropriate systems for patrol work. With the widespread use of these systems, citizen participation and administrative management should be coordinated appropriately. This paper focuses mainly on road management patrols - which is a common issue nationwide - and utilizes the "My City Report" (MCR) project that is being developed as the next generation version of the Chiba-repo system. This project was researched for three years with the support of funds from the National Institute of Information and Communications Technology. A total of 15 local governments-including Chiba City-participated in the demonstration experiment.

Therefore, our purpose is to develop a platform that all local governments can use in common and share as open source, and to examine its applicability. This article explains the construction status of "platformization" (Raetzsch et al., 2019), focusing on the management of city infrastructure via citizen collaboration and discussing the achievements and obstacles of the current system.

\section{The development of the My City Report application}

The core of the development of the MCR platform is a smartphone application for accepting contributions- 
such as reports on city faults - from citizens as well as an internal management tool for sharing information from citizens with the appropriate departments. It also includes a suitable response policy within the local government based on the information received. The application is cloud-based and should offer the ability to share information with neighboring municipalities, assuming joint operations in multiple local governments in the future. Considering the diverse circumstances within the information communication environment in municipalities, it was decided to develop the application on an open source basis as far as possible. Therefore, assuming existing tools and operational flows within municipalities, in addition to the public part on the citizen side, it was found that certain functions on the administrative side are also necessary. Therefore, we used the Ruby on Rails based web project management opensource software "Redmine" for software development.

Figure 1 shows that the management tool can set the status of management, priority, person in charge, update date, and disclosure setting, among other functions. This can be done for each individual post. It also has a function that allows output of a standard daily work report in PDF format. An email is automatically sent to the administrator of the department linked to the reporting category at the time of reporting via the smartphone application.

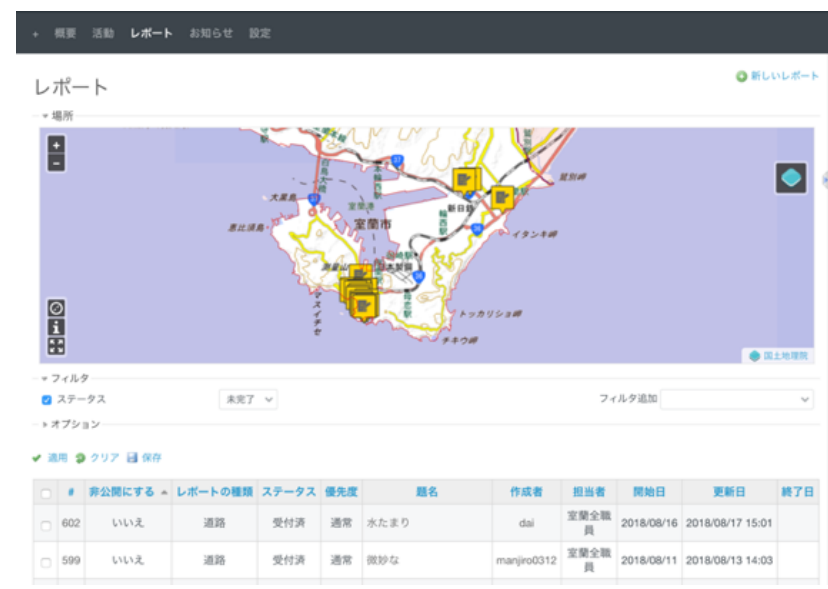

Figure 1. Administration function of the My City Report web application

This application for citizen reporting was originally constructed as a web application at the designing and testing stage. However, considering that the map displays and post information will increase when it is in operation, the smartphone application can be seen as a native application. The application was completed and released for both iOS and Android in March 2018 (Figure 2). During development, we used "Expo" as a service to support build and function verification and a JavaScript based framework - "React Native"- to develop both applications with one source code. The advantage of using Expo is that it can be used in a limited environment when performing beta testing by using smartphone apps and management tools, for example within a municipal organization. Furthermore, there is no need to process the application each time you upgrade - as with the iOS and Android applications - and therefore functionality can frequently be improved according to the experimental situation.

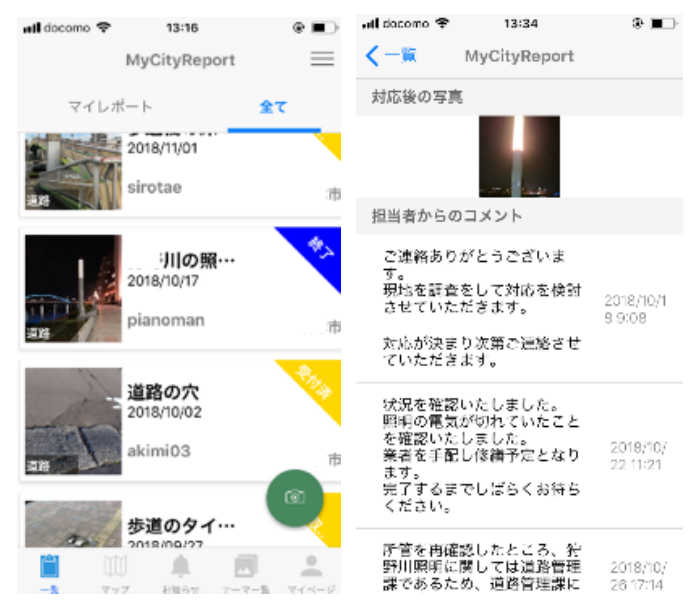

Figure 2. My City Report smartphone application for citizen reporting

Categories for posts within the application can be arbitrarily set by coordinating with each department of a municipality. For example, "faults report" is for problems in public areas such as roads and parks and citizens themselves can voluntarily start garbage collection. There are three types of "Self-resolving reports" that posts the results of the citizen report, such as "Theme report," which is not limited to town problems but is posted within a certain theme. Additionally, reports that the municipality has confirmed and matched to citizen submissions and have made public are developed using an Application Programming Interface (API) that can be acquired in JavaScript Object Notation (JSON) format - and includes Japanese - in compliance with GeoReport API version 2 of the Open 311 protocol. This makes it possible to compare posts among cities that have introduced the My City Report system and to incorporate data into other applications.

Table 1 summarizes the feedback from the local governments concerning the development of applications for citizen collaboration. The most common issue was the demand for a smartphone application and many comments stating that an easy-to-understand interface and simple operation procedures for citizens are required. Furthermore, citizens' reporting emphasized the function of the manager mode. In the case of Japanese local governments in particular, the work derived from a citizen report needed to be divided into multiple sections, which revealed that if the contents of the issue submitted had to be divided into other sections, many functions similar to Customer Relationship Management (CRM) platform were required. There were a few feedback comments concerning system operation, and many feedback comments are related with the improvement of the management function by local government officer. 
(unit: the amount of feedback comments)

\begin{tabular}{|l|c|c|c|c|}
\hline \multicolumn{1}{|c|}{ Category } & FY 2016 & FY 2017 & FY 2018 & Total \\
\hline Smartphone App. & 33 & 150 & 174 & 257 \\
Administration & 39 & 31 & 96 & 166 \\
functions & & & & \\
Web Pages & 0 & 10 & 2 & 12 \\
Both functions & 0 & 6 & 5 & 11 \\
System & 0 & 22 & 0 & 22 \\
Operations & 72 & 219 & 177 & 468 \\
Total & & & & \\
\hline
\end{tabular}

Table 1. Feedback comments for prototype of MCR for citizens application

\section{Demonstration and utilization of the My City Report application}

Concerning the citizen submission tool and the municipality manager tool of the My City Report, from the fiscal year 2017, the function verification by municipalities of the prototype and the open demonstration experiment were carried out in certain cities. Based on this result, Muroran City implemented the system from April 2018 and Numazu City implemented it in July 2018, starting a long-term demonstration experiment that accepts regular reporting from citizens. These cities simultaneously ran a workshop to utilize My City Report through the participation of the general public.

For example, the "My City Report Walking Tour Event in Muroran City" was held on August 5th, 2018, with about 10 participants from the general public. At the event, the city's infrastructure and urban planning was explained by city personnel, and approximately 30 reports were made by the participants walking in town for about two hours afterwards. Currently, Muroran City accepts complicated reports in categories such as roads and parks, among others. This way of reporting leads to the finding of many defects on the sidewalk, unclear signs, and damage on the road surface; problems that cannot normally be found easily.

\section{Developing a real-time road monitoring dashboard for road manager}

In addition to the system that obtains data through citizen reporting, we developed routine patrol support tools for road managers. This dashboard system combines the data acquired through the smartphone application (Maeda et al., 2018) for the real-time detection of road damage images and the geospatial data held by municipalities (Figure 3). The real-time road damage image detection application is created specifically for road management by using computer vision and machine learning technology. To develop this application, we acquired approximately 160,000 road images and selected 9,053 images to published "Road Damage Detector" on Github (https://github.com/sekilab/RoadDamageDetector). The data set contains the bounding box of each class for the eight types of road damage specified. Each image is extracted from an image set created by capturing pictures of a large number of roads obtained by using a vehiclemounted smartphone (Figure 4).

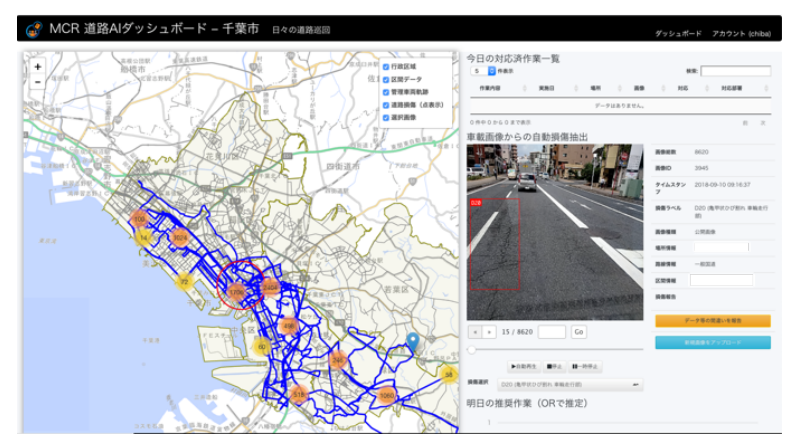

Figure 3. Real-time road monitoring dashboard for road managers

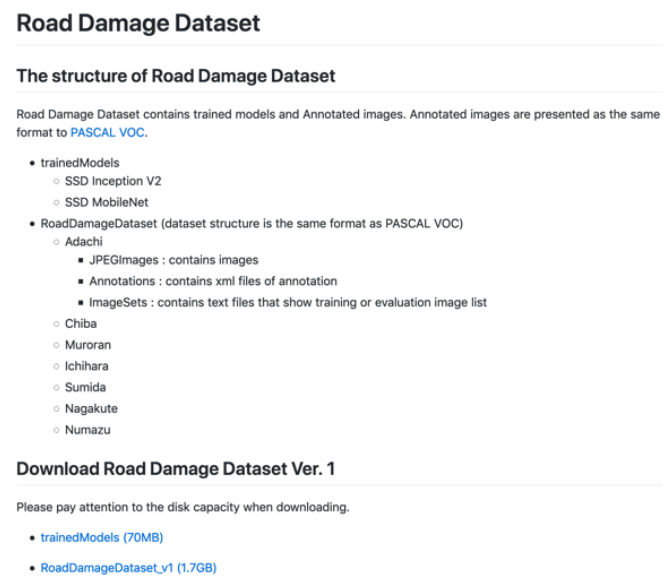

Figure 4. Published road damage dataset and road damage detector application on Github

However, local government officials often wish to make decisions concerning what they should prioritize for repair along with basic the status of the roads such as road type, traffic volume, and the distribution of road flaws. Therefore, we built a function that displays this information on the dashboard for road administrators. On this system (Figure 5), the basic statistics such as the road extension of each municipality, the number of local government staff, and the budget of the civil engineering department can be displayed on the dashboard The total distance of the municipal road extension covers approximately $1,060,000 \mathrm{~km}$ nationwide, and there are about 37,600 civil engineers employed by local governments nationwide. However, there are only 1470 specialized road repair workers and only 230/1,728 local governments nationwide in 2017. It is important to utilize data from various perspectives promptly and efficiently, such as patrol observation data from municipal employees and citizen reports. 


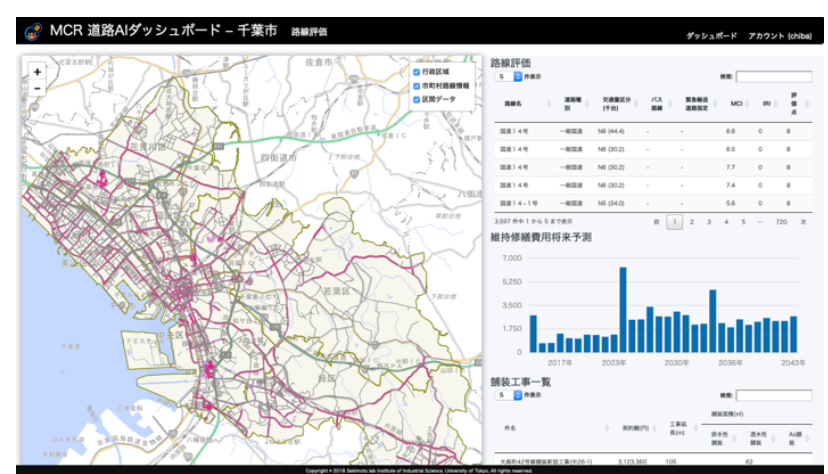

Figure 5. Road statistics function for road managers
Conceptualizing City APIs as elements of infrastructures, Big Data \& Society, 6(1), https://doi.org/10.1177/2053951719827619

Schuurman, N. (2000). Trouble in the Heartland: GIS and its Critics in the 1990s, Progress in Human Geography, 24(4), 569-590, https://doi.org/10.1191/030913200100189111

Xu, L., Kwan, M-P., McLafferty, S. and Wang, S. (2017). Predicting demand for 311 non-emergency municipal services: An adaptive space-time kernel approach, Applied Geography, 89, 133-141, https://doi.org/10.1016/j.apgeog.2017.10.012

\section{Conclusions}

This paper described the platform development of the My City Report, which is aimed at improved citizen collaboration concerning the maintenance and management of roads and at improving the efficiency of management by local governments. This platform makes it possible for citizens and municipalities to collaborate using cloud-based automatic detection for road administrator patrols and offer additional functions such as visualization of the situation on a dashboard display, so that visibility with diverse subjects Information sharing is expected. We are also planning to make the developed source code available and to release the API in 2019. By doing this, we plan to build a community of citizens and municipalities that use My City Report widely in local government. Citizen reports concerning faults or problems can be actively dealt with in real time. The platform not only spreads the work but also provide guidelines on what kinds of posts are required. Lastly, the platform can also assist in organizing voluntary collaborations by citizens.

\section{Acknowledgements}

We would like to express our gratitude to Chiba city, Muroran city and Numazu city office for their cooperation with the experiment in 2018. This article was partly supported by the JSPS KAKENHI Grant No. 17K17658.

\section{References}

Haklay, M. (2013). Neogeography and the Delusion of Democratisation, Environment and Planning A:

Economy and Space, 45(1), 55-69, https://doi.org/10.1068/a45184

Maeda, H., Sekimoto, Y., Seto, T., Kashiyama, T. and Omata, H. (2018). Road Damage Detection and Classification Using Deep Neural Networks with Smartphone Images, Computer-Aided Civil and Infrastructure Engineering, 33(12), 1127-1141, https://doi.org/10.1111/mice.12387

Pánek, J. (2016) From Mental Maps to GeoParticipation, The Cartographic Journal, 53(4), 300-307, https://doi.org/10.1080/00087041.2016.1243862

Raetzsch, C., Pereira, G., Vestergaard, L. S. and Brynskov, M. (2019). Weaving seams with data: 